\title{
Evaluation of the Damage Initiation of a Composite Thin-Walled Structure, on the Example of the ADUSTER Gyroplane Undercarriage
}

\author{
Karol Szklarek', Patryk Różyło ${ }^{1 *}$ \\ 1 Faculty of Mechanical Engineering, Lublin University of Technology, Nadbystrzycka 36, 20-618 Lublin, Poland \\ * Corresponding author's e-mail: p.rozylo@pollub.pl
}

\begin{abstract}
The subject of the research was a undercarriage leg of a gyroplane made of composite materials. The aim of the work was to assess the level of damage initiation of the composite gyroplane undercarriage. In the study, a structural capacity analysis was carried out, taking into account the phenomenon of damage initiation. Numerical calculations were conducted based on the finite element method in the ABAQUS ${ }$ software. The issue was solved according to the Newton-Raphson algorithm.
\end{abstract}

Keywords: Numerical analysis, FEM, ABAQUS, Failure.

\section{INTRODUCTION}

Modern engineering approach assumes the use of new types of materials - commonly referred to as composite materials. Composite materials are increasingly used in the aerospace, construction and automotive industries. Due to the special properties, such as high load capacity and stiffness, these materials are widely used as thin-walled structures $[1,9,12]$. Thin-wall composite structures subjected to significant overloads are exposed to the initiation of destruction and successively loss of load capacity [1,9-11]. Identification of the parameters causing the initiation of the destruction process of the laminate structure is a problem described by the researchers. This is due to the complex nature of the destruction of the composite material which depends on many factors, making it difficult to unambiguously evaluate the entire process [8]. The description of the composite destruction phenomenon is usually carried out on the basis of material boundary conditions determined in experimental studies $[1,3]$. The use of actual models describing the initiation criteria of destruction has found wide application in commercial software using the finite element method, such as the
ABAQUS®. The widest use was found, for the Tsai-Wu's [14], Tsai-Hill's [13], Azzi-Tsai-Hill's [3] and maximum stresses [4] criteria. Tsai-Wu's tensor criterion [14] has the most actual significance in relation to the criteria based on the destruction of the first layer of laminate, while maintaining the absence of the phenomenon of delamination. There are observed many other more advanced criteria, such as LaRC03 (2-D) or the Hashin's criterion, but the work has shown the influence of the basic four criteria. The work involved numerical analysis based on the use of the finite element method in the ABAQUS ${ }^{\circledR}$ software $[1,2,5,7]$. The analysis was carried out using the known criteria of damage initiation. In this study, the widespread use of composite materials was used to analyse the load capacity of the structure of the ADUSTER undercarriage leg.

\section{SUBJECT OF THE STUDY}

The subject of the study was the undercarriage leg prototype of the ADUSTER folding gyroplane undercarriage. The leg structure was based on carbon-epoxy composite structures. The top layer (red colour) consisted of an inclined 
carbon fabric laid at an angle of $+/-45^{\circ}$ in relation to the direction of the leg span. The bottom layer of the discussed structure consisted of ten layers of fabric, the other of five. The thickness of a single layer was $0.2 \mathrm{~mm}$. The top layer covered the inside sections (blue) and the reinforcement of the leg's edges (green) also made of five layers of carbon fabric and with the arrangement of fibres identical to that of the top layer. Elements made of carbon fabric were used to shape and glue the leg from the outside. The main load-bearing element (orange colour) was a modular composite with fibres running along the leg - roving. The undercarriage leg's structure is shown in Figure 1.

The method of mounting the leg's wheel is shown in Fig. 2a. The leg's wheel is mounted on the wheel axis 1 (Fig. 2a), which is secured with bolts in a specially adapted place. The place of assembly of the wheel axis is protected from excessive pressure by steel plates 2 located on both sides of the leg. The gyroplane's wheel axis is welded to one of the plates. In the leg's mounting holes are equipped with aluminium contact sleeves 3 protecting the composite.

The leg is attached to a gyroplane on a rotary axis, the rotation of which allows the undercarriage to be folded (Fig. 2b). The leg has an opening for the axis of its rotation, which is used to fold the undercarriage. The beginning and end of this opening are secured with steel contact sleeves 4 and connected with an aluminium pipe 5 . The disc 6 located on the outside of the shell serves to support the leg against the hull of the gyroplane in a specially adapted place.

For leg's elements made of composite fabric, an orthotropic material model was defined in a uniaxial state of stress with the following mechanical and boundary properties - Table 1 :

For leg's elements made of carbon roving, the orthotropic material model with mechanical properties shown in Table 2 was defined.

In the numerical models developed for metal elements, models of elastic-plastic material with the following mechanical properties were adopted:

- 30H2N2M steel - the material was used for the following elements: wheel axis with mounting plates and elements protecting the leg's axis (Table 3).

- 7075-T6 aluminium alloy - the material was used for the elements protecting the connection of the wheel axis with the leg - contact sleeves (Table 4).

\section{RESEARCH METHODOLOGY}

The studies were carried out to assess the correctness of the structure in terms of meeting the strength conditions specified by the CS-VLA 479 aviation regulations. The studies were conducted using the finite element method, using the ABAQUS® software as a computational tool. For the numerical calculations, nonlinear stability
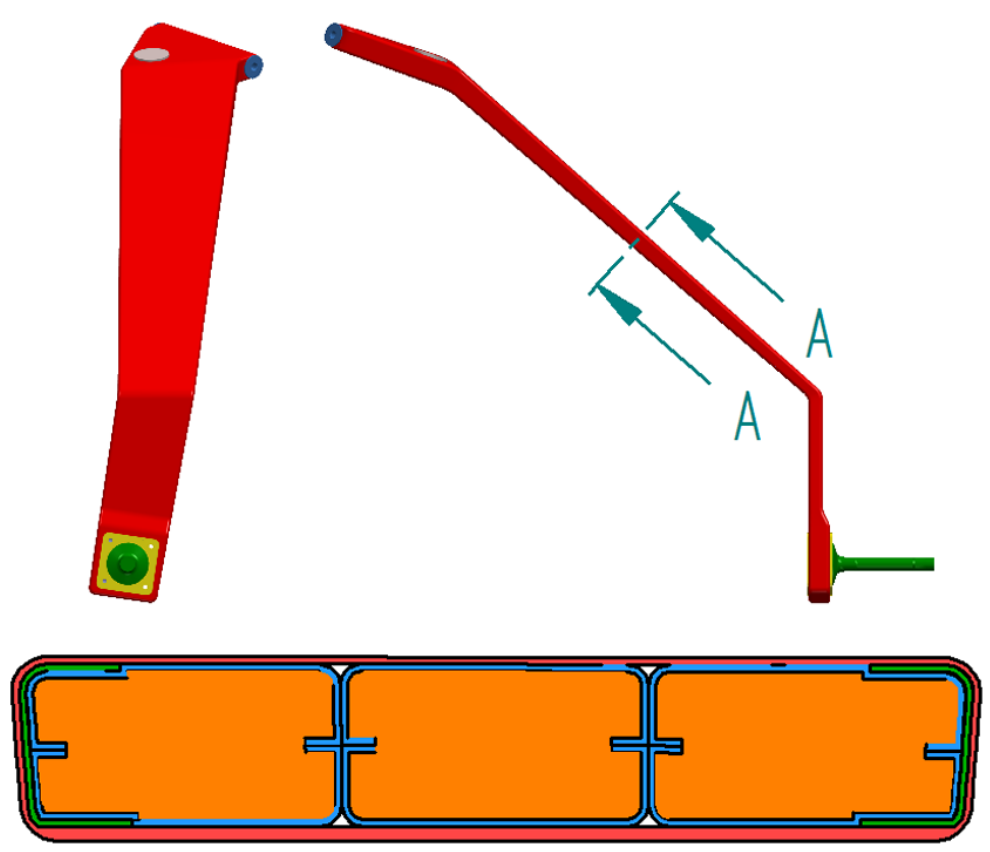

Fig. 1. The undercarriage leg's structure of the ADUSTER gyroplane. 
a)
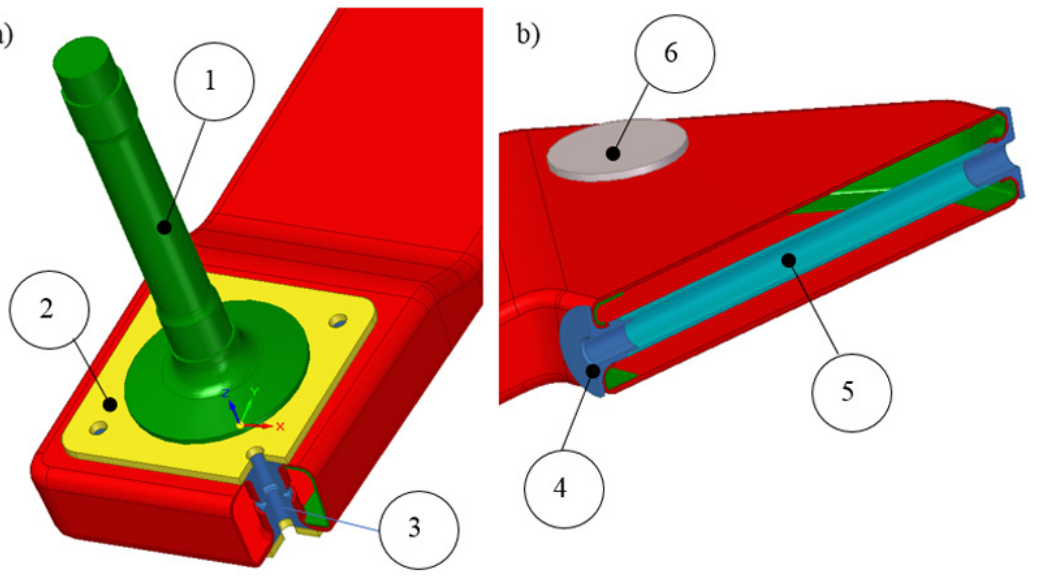

Fig. 2. Undercarriage leg's structure: a) wheel assembly location, b) the place of connection of the leg with the gyroplane.

Table 1. Material properties of composite - CFRP (woven) [6]

\begin{tabular}{|l|c|}
\hline Young Modulus $\mathrm{E}_{1}=\mathrm{E}_{2}[\mathrm{MPa}]$ & 60000 \\
\hline Poisson Ratio v [-] & 0.27 \\
\hline Kirchhoff's Modulus $\mathrm{G}_{12}[\mathrm{MPa}]$ & 4550 \\
\hline Kirchhoff's Modulus $\mathrm{G}_{13}=\mathrm{G}_{23}[\mathrm{MPa}]$ & 10800 \\
\hline Tensile Strength - Fiber Xt [MPa] & 621 \\
\hline Compression Strength - Fiber Xc [MPa] & 760 \\
\hline Tensile Strength - Matrix Yt [MPa] & 594 \\
\hline $\begin{array}{l}\text { Compression Strength - Matrix Yc } \\
\text { [MPa] }\end{array}$ & 707 \\
\hline Shear Strength $\mathrm{S}_{12}[\mathrm{MPa}]$ & 125 \\
\hline
\end{tabular}

Table 2. Material properties of composite [1]carbon roving

\begin{tabular}{|l|c|}
\hline Young Modulus $\mathrm{E}_{1}[\mathrm{MPa}]$ & 131700 \\
\hline Young Modulus $\mathrm{E}_{2}=\mathrm{E}_{3}[\mathrm{MPa}]$ & 6360 \\
\hline Poisson Ratio $\mathrm{v}_{12}[-]$ & 0.32 \\
\hline Poisson Ratio $\mathrm{v}_{13}=\mathrm{v}_{23}[-]$ & 0.05 \\
\hline Kirchhoff's Modulus $\mathrm{G}_{12}[\mathrm{MPa}]$ & 4180 \\
\hline Kirchhoff's Modulus $\mathrm{G}_{13}=\mathrm{G}_{23}[\mathrm{MPa}]$ & 4180 \\
\hline
\end{tabular}

Table 3. Material properties - Steel 30H2N2M

\begin{tabular}{|l|c|}
\hline Young Modulus E [MPa] & 210000 \\
\hline Poisson Ratio v [-] & 0.3 \\
\hline Yield Strength Re [MPa] & 830 \\
\hline Tensile Strength Rm [MPa] & 980 \\
\hline Elongation at break [\%] & 11 \\
\hline
\end{tabular}

Table 4. Material properties -Aluminium alloy 7075-T6

\begin{tabular}{|l|c|}
\hline Young Modulus E [MPa] & 71700 \\
\hline Poisson Ratio v [-] & 0.33 \\
\hline Yield Strength Re [MPa] & 503 \\
\hline Tensile Strength Rm [MPa] & 572 \\
\hline Elongation at break [\%] & 13 \\
\hline
\end{tabular}

analysis based on the Newton-Raphson algorithm was used $[1,15]$. The use of a composite material model with specified boundary values of the composite, made it possible to carry out calculations using the initial criteria of destruction of the composite: Tsai-Wu's, Tsai-Hill's, Azzi-Tsai-Hill's, maximum stresses - MSTRS.

\section{Discrete model}

The discrete model was developed based on the geometrical model of the analysed structure. The structures made of carbon fabric, the leg's surface layer and profiles, were discretised using S4R 4-node conventional shell elements. Leg's elements designed for strengthening its edges, were discretised using SC8R eight-node continuum shell elements. In both cases finite elements had the function of first order shape and reduced integration. Reduced integration technique is associated with the removal of false forms of deformations occurring in the calculation of higher order polynomial to obtain the correct value of averaged results under the condition of stressdisplacement occurring at nodes [15]. The adopted finite element types allowed for defining 
the structure of the composite based on the finite element thickness. Components made of a modular composite (Roving) were discretised using type C3D10 tetragonal solid elements, constituting 10-node elements with the function of the second-order shape. The discretisation of metal elements was carried out using type C3D8R hexagonal solid elements, constituting 8-node elements having the function of first-order shape and reduced integration.

The cooperation between the composite elements of the model was obtained by using Tie type interactions, permanently connecting the finite element mesh of individual cooperating surfaces. This method of modeling allowed for even transmission of loads and displacements between connected leg construction elements. The discrete model of the leg of the gyroplane undercarriage is shown in Figures 3 and 4.

The number of mesh elements and the number of nodes obtained for the carried out discretisation are presented in Table 5.
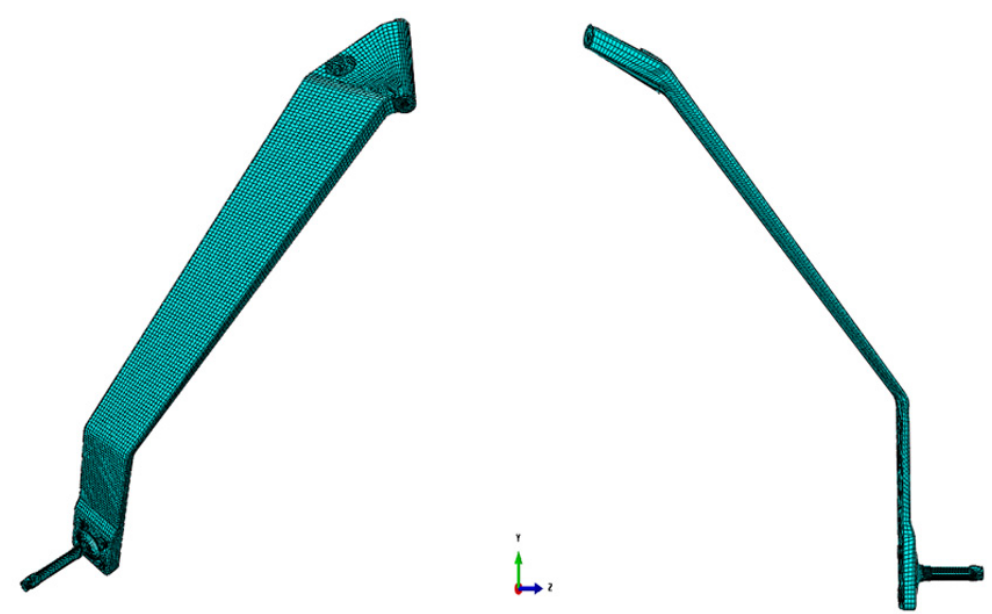

Fig. 3. The discrete model of the undercarriage leg - general view
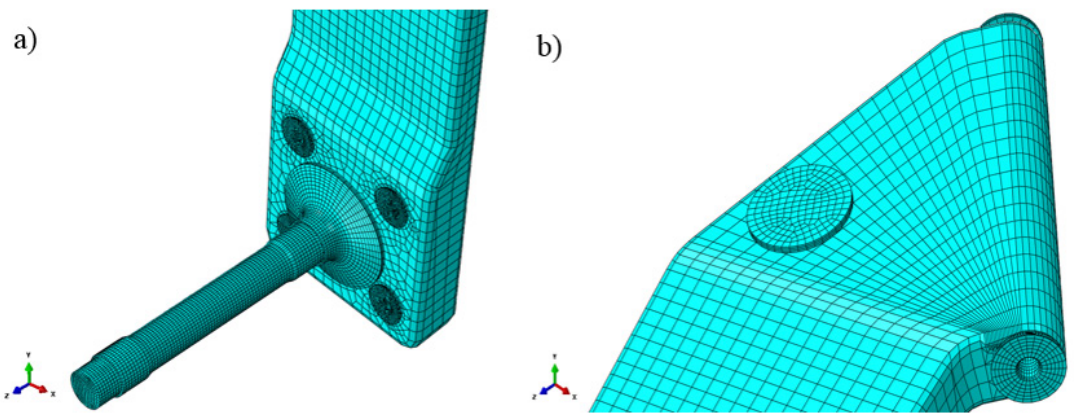

Fig. 4. The discrete model of the undercarriage leg: a) place of connection to the wheel axis, b) the place of connection to the hull 


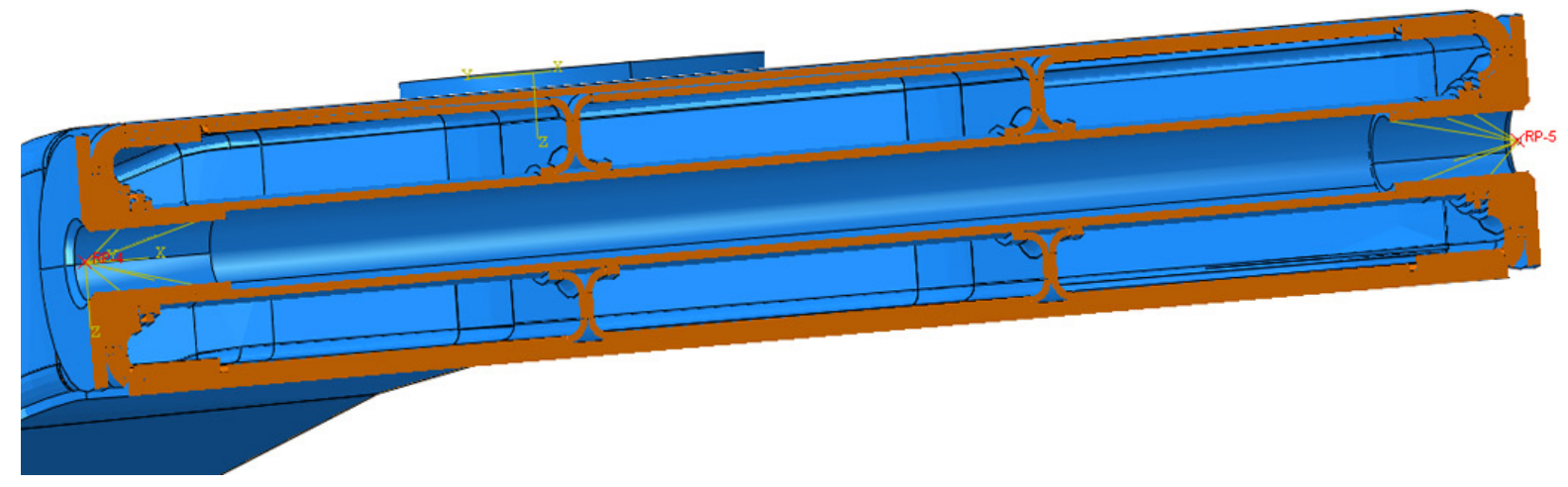

Fig. 5. Boundary conditions - undercarriage leg - gyroplane's hull mounting

The second defined boundary condition was the support of the leg with the gyroplane's hull in a specially designed place. In this case, the possibility of displacement of the support area nodes in the direction perpendicular to the leg - hull support plane was blocked. Thus the implementation of boundary conditions was carried out in the local coordinate system, blocking displacements of nodes in the direction perpendicular to the supporting surface - Figure 6.

The structure load was realized by applying forces in the gyroplane wheel mounting area. In the numerical model, a local coordinate system was created on the wheel axis, ensuring the appropriate angle between the propeller axis and the direction of the $\mathrm{X}$ axis with the value of $38.14^{\circ}$. The load components were applied at the RP reference point, located in the axis of the circle - halfway between the spacing of its bearings. The load was coupled to the cylindrical surface of the axis by Coupling interaction. The method of implementing the model load is presented in Fig. 7.

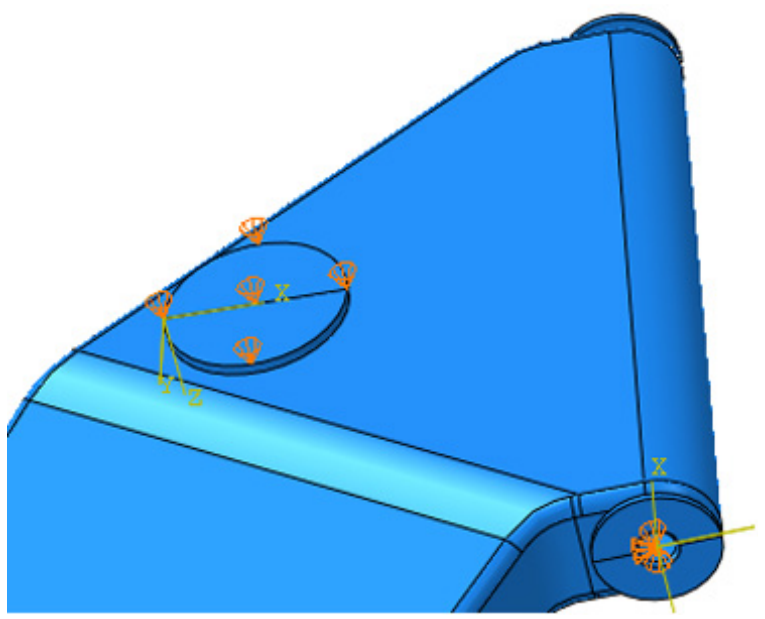

Fig. 6. Boundary conditions - leg - hull support location
The calculations carried out for two load cases:

- Case 1: Fz force directed upwards, Fx force directed to the back of the gyroplane,

- Case 2: Fz force directed upwards, Fx force directed to the front of the gyroplane

In the calculations the values of destructive forces were assumed: $\mathrm{Fz}=17334 \mathrm{~N}$ and $F x= \pm 4334 \mathrm{~N}$, according to the diagram shown in Figure 8.

\section{RESULTS OD NUMERICAL ANALYSIS}

Numerical analysis indicated the initiation areas for the destruction of composite elements made of carbon fabric. The destruction initiation sites for the first load case were located in the areas of refraction of the leg's geometry and support against the hull. Damage to the composite in the area of support against the hull was caused by a change in the stiffness of the structure and the occurrence of reaction forces resulting from supporting the leg against the hull of the gyroplane.

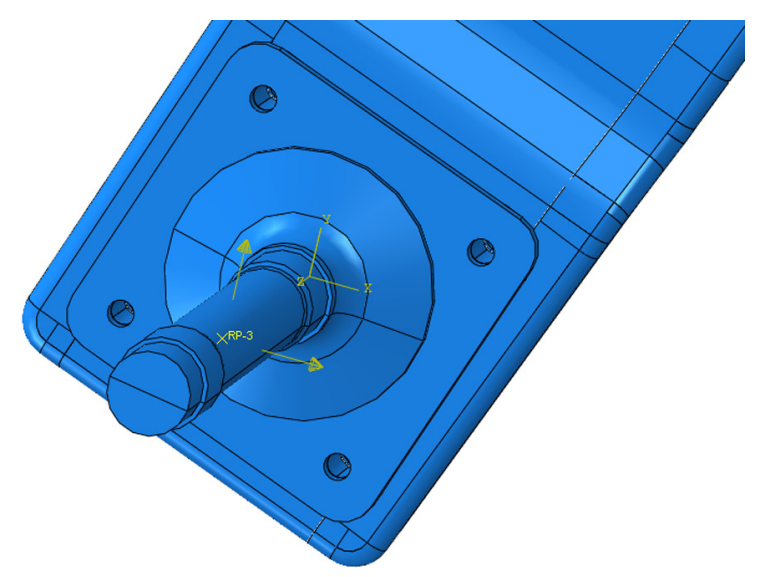

Fig. 7. The implementation of the load to the undercarriage leg model 


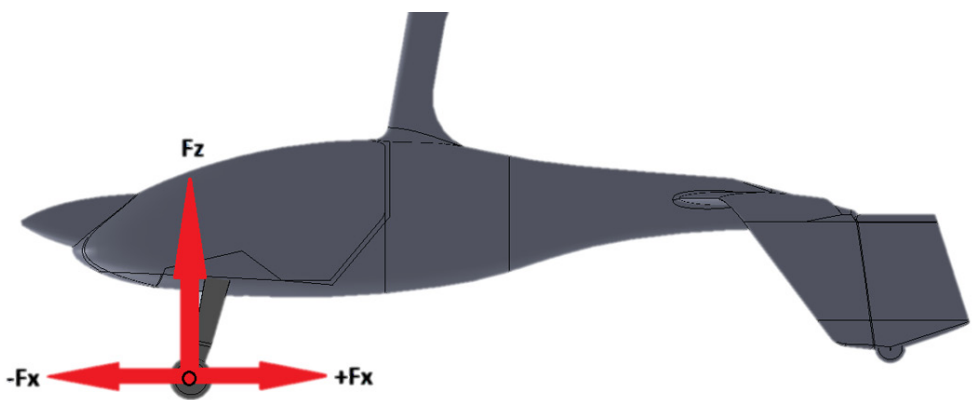

Fig. 8. Load diagram of the gyroplane's undercarriage leg

This effect also affected the lower surface of the leg in this area. Another localised area of damage was the point of inflection of the leg's geometry in its lower part. The load on the tested structure causes tensile stress which leads to damage in the bottom layer of the bend. This area is heavily bent.

The evaluation of the destruction initiation for the discussed points was carried out using four criteria of destruction of the composite. The obtained criteria values in the nodes for the points discussed are shown in Fig. 10. The area exposed the most to destruction is the point of leg's support against the hull.

The areas of destruction initiation for the second load case are shown in Fig. 11.

The obtained values of the failure criteria in the nodes for the second load case are summarised in Fig. 12. On the basis of the obtained results, the identity of the results of areas prone to destruction was demonstrated.

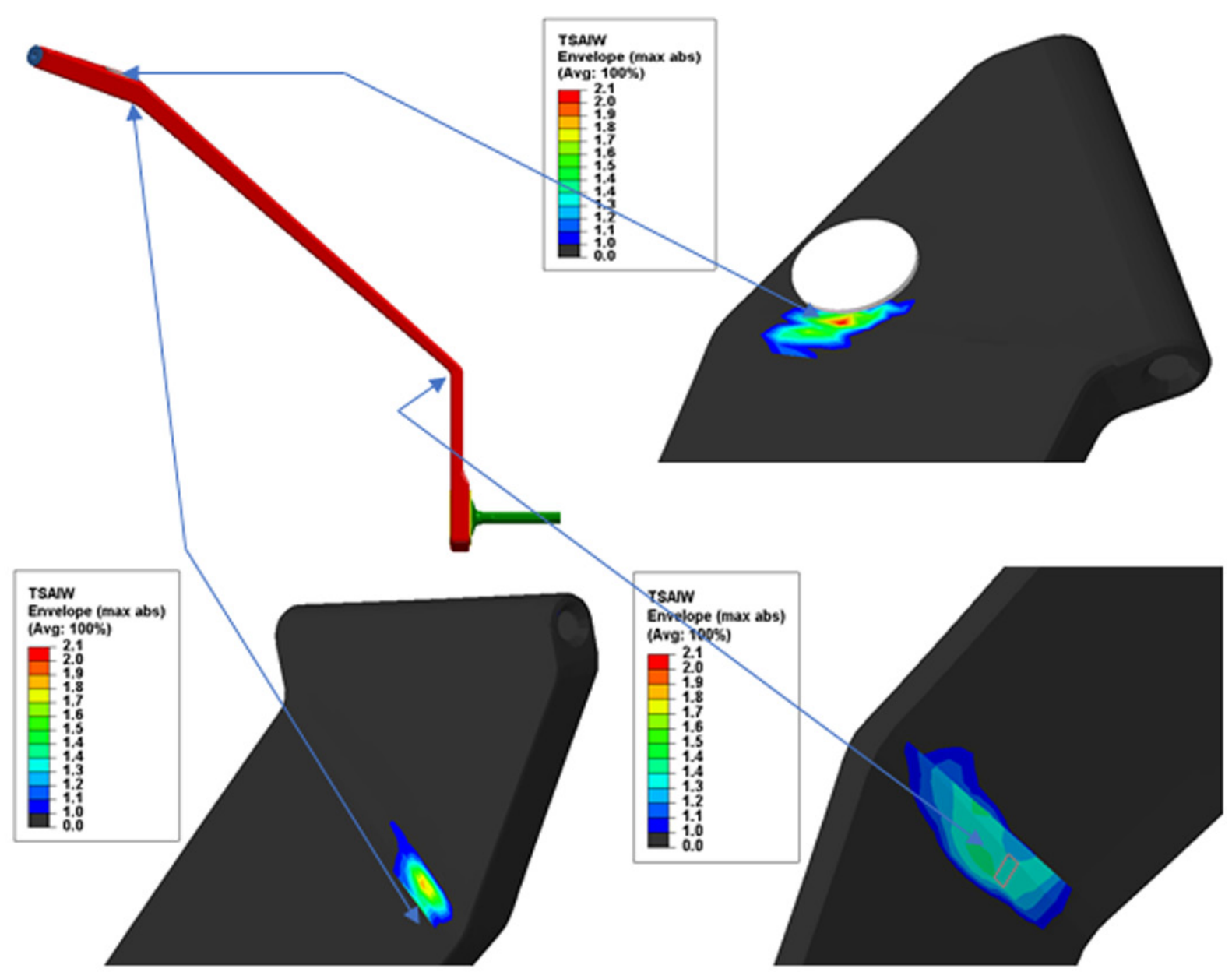

Fig. 9. The first load case: 1) Location of destruction initiation points for the first load case, 2) destruction at the point of leg's support against the hull 3) destruction at the point of leg's support against the hull on the bottom surface 4) destruction at the point of inflection of leg's geometry. 


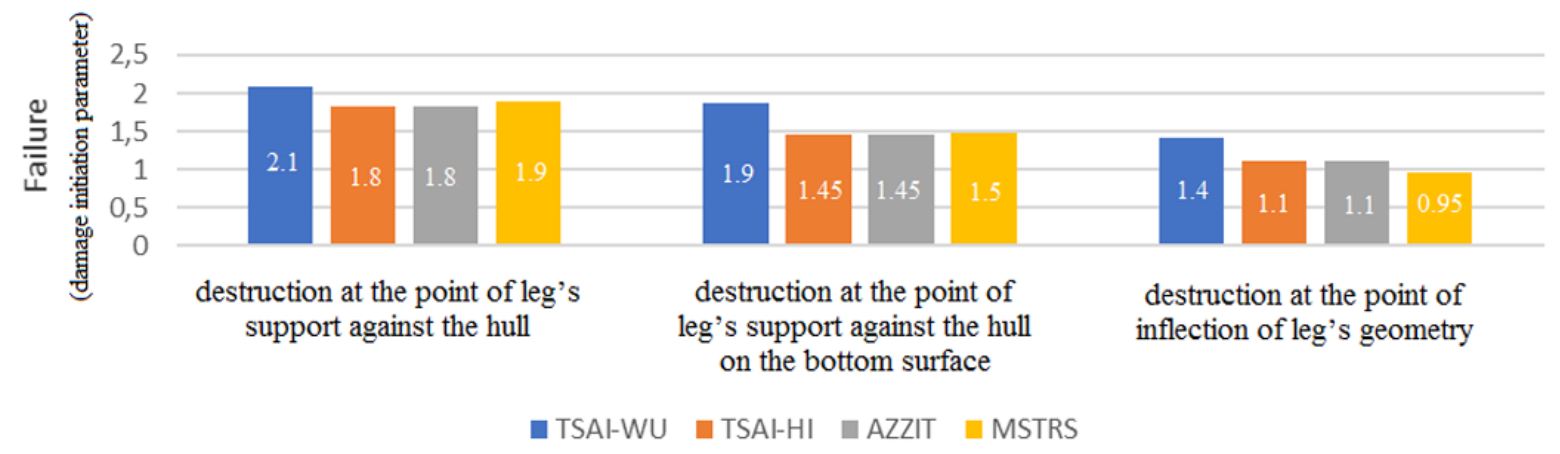

Fig. 10. Comparison of the destruction criteria values for the first load case

1)

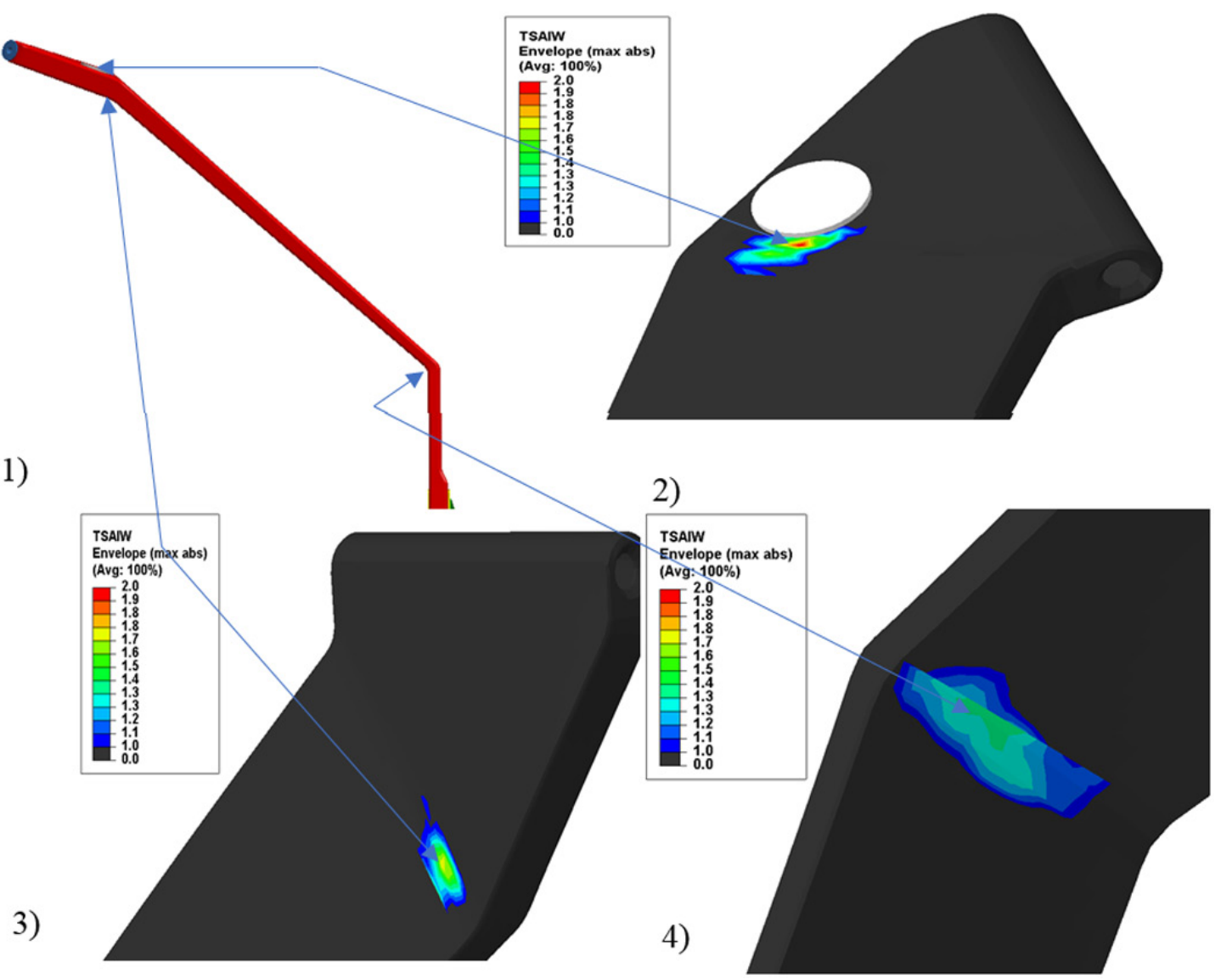

Fig. 11. The first load case: 1) Location of destruction initiation points for the second load case, 2) destruction at the point of leg's support against the hull, 3) destruction at the point of leg's support against the hull on the bottom surface, 4) destruction at the point of inflection of leg's geometry.

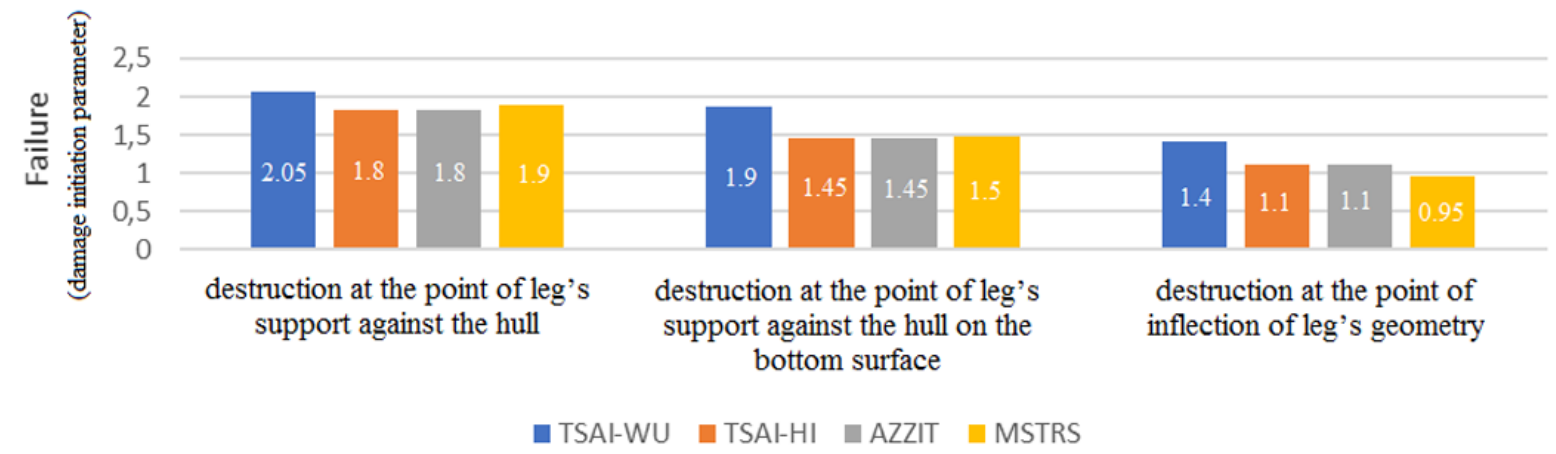

Fig. 12. Comparison of the destruction criteria values for the second load case 


\section{CONCLUSIONS}

The study presents FEM based load tests of the prototype composite structure of the undercarriage leg for the ADUSTER gyroplane. In the simulation research, the correctness of the structure in terms of initiating the destruction of the carbon-epoxy composite was checked. Based on the carried out simulations, the following conclusions were made:

- in both cases of loads, damage was observed in elements made of carbon-epoxy fabric,

- the destruction initiation places are identical for both cases of leg's load.

The conducted analysis showed a high qualitative and quantitative level of the obtained research results, for both cases. In both load cases, the destruction initiation points have identity. The values of the damage criteria are slightly higher in the first load case.

\section{REFERENCES}

1. Debski H. Experimental investigation of postbuckling behavior of composite column with tophat cross-section. Eksploatacja i Niezawodnosc Maintenance and Reliability 2013; 15(2): 106-110.

2. Debski H, Koszalka G, Ferdynus M.: Application of fem in the analysis of the structure of a trailer supporting frame with variable operation parameters. Eksploatacja i Niezawodnosc - Maintenance and Reliability 2012; 14(2): 107-114.

3. German J.: Podstawy mechaniki kompozytów włóknistych. PK, Kraków, 2001.

4. Jenkins C.F.: Materials of construction used in aircraft and aircraft engines. Report to the Great Britain Aeronautical Research Committee, 1920.

5. Nieoczym A., Szklarek K.: Finite Elements
Strength Analysis of a Compressor Consisting of Four Helical Rotors. Adv. Sci. Technol. Res. J. 2018; 12(1): 1-8.

6. Mendes P.A.A.E., Donadon M.V.: Numerical prediction of compression after impact behavior of woven composite laminates. Composite Structures 2014; 113: 476-491.

7. Rozylo P.: Optimization of I-section profile design by the finite element method. Adv. Sci. Technol. Res. J. 2016; 10(29): 52-56.

8. Reddy JN, Pandey AK.: A first-ply failure analysis of composite laminates. Computation Structures 1987; 25(3): 371-393.

9. Rozylo P.: Experimental-numerical test of open section composite columns stability subjected to axial compression. Archives of Material Science and Engineering 2017; 84(2): 58-64.

10. Rozylo P.: Numerical analysis of the postbuckling of thin-walled composite structure with z-profile cross section. Adv. Sci. Technol. Res. J. 2018; 12(2): 52-58.

11. Rozylo P, Debski H, Kral J. Buckling and limit states of composite profiles with top-hat channel section subjected to axial compression. AIP Conf Proc 2018;1922:080001.

12. Rozylo P., Lukasik D.: Numerical analysis of the critical state of thin-walled structure with z-profile cross section. Adv. Sci. Technol. Res. J. 2017; 11(1): 194-200.

13. Tsai SW.: Strength Theories of Filamentary Structures in Fundamental Aspects on Fibre Reinforced Plastic Composites. Conference Proceedings, R. T. Schwartz and H. S. Schwartz (Editors), Dayton, Ohio, 24 - 26 May 1966, Wiley, New York, 1968.

14. Tsai SW., Wu EM.: A general theory of strength for anisotropic materials. Journal of Composite Materials 1971; 5(1): 58-80.

15.Zienkiewicz O.C., Taylor R.L.: Finite Element Method (5th Edition) Volume 2 - Solid Mechanics. Elsevier, 2000. 